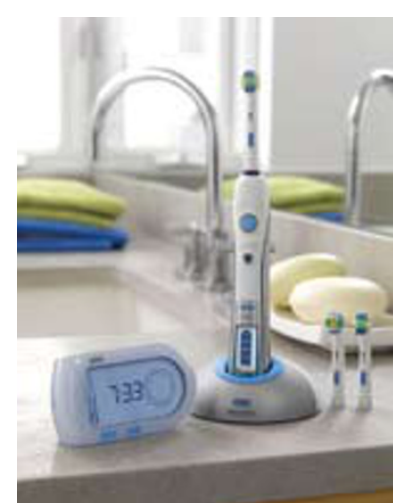

\section{RETAIL GIANTS BOOST AWARENESS OF NSM}

This year's British Dental Health Foundation National Smile Month (NSM) campaign was boosted by the involvement of the retail sector, according to $P \& G$, one of the sponsors. $P \& G$ believe the expansion into retail was a logical progression for the campaign. The manufacturer of Oral-B has strong links with retail partners including Amazon, Superdrug, Argos, Sainsbury's, Morrisons and Tesco. Razi Hyder, Country Manager at P\&G commented: 'We've worked hard with these retailers to extend and increase the visibility of the campaign. The combined effort of the profession and retailers will strengthen the campaign and make sure the key oral health messages are seen by a larger audience.'

Reader response number 55

\section{CUT THE RISK OF INFECTION}

The risk of infection in the surgery is a concern for all practitioners.

A surgery is a breeding ground for micro-organisms, however, the risk of contamination can be greatly reduced by following good hygiene procedures

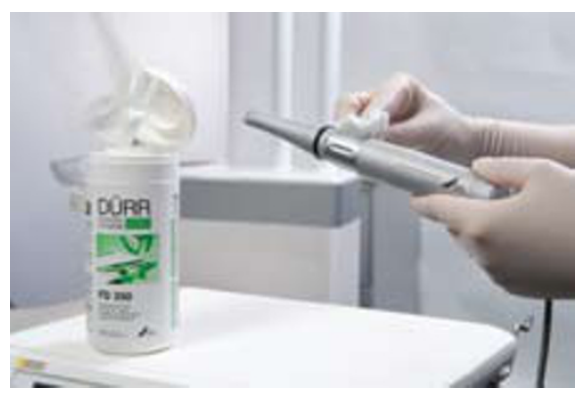
using quality products.

Dürr Dental manufactures a range of hygiene products that are conveniently colour coded to identify each product's application. In addition, all of Dürr's hygiene products are designed to be time-saving, practical and above all pleasant and gentle on the user. All are pleasantly scented and are mainly aldehyde-free.

If you would like more information please call without obligation on 01536526740. Alternatively you may like to email info@duerruk.com.

Reader response number 56

\section{SPECIALIST INFORMATION FOR DCPS}

NHS Evidence - oral health is a freely available collection of guidelines, critical summaries of systematic reviews and patient information from trusted organisations - a key resource for DCPs who want to stay up-to-date.

During National Smile Month (16 May -

16 June) this collection is launching its latest

Annual Evidence Update: a summary of the

best available information published during

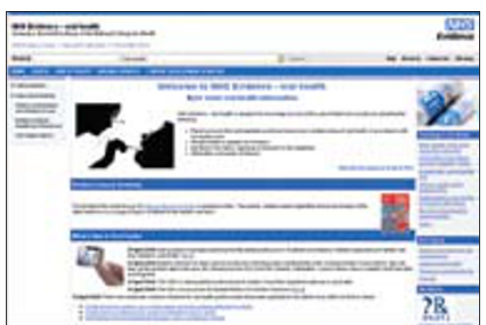

the previous year.

The collection is updated on a daily basis and users will also find news stories, details of events and relevant information from oral health organisations.

Provided by NICE, NHS Evidence launched in April 2009 with the aim of providing fast and easy access to evidence-based health and social care information.

See www.library.nhs.uk/oralhealth/

Reader response number 57
COMFORT WITH COLOUR

Dürr Dental's colourful range of universal cannulas are available in both $16 \mathrm{~mm}$ and $11 \mathrm{~mm}$ sizes. They aspirate large amounts of secretions with the minimum of noise even when operated at high volume flow, and can be relied upon to minimise aerosol-cloud, thus protecting operator and assistant.

The cannulas are designed with the patient's comfort in mind as well and they are also autoclavable at $134^{\circ} \mathrm{C}$. Available in turquoise, royal blue, bright pink, yellow or orange as well as the more conventional grey, you also have a choice of size - either adult or child. To bring a little sunshine to your suction system call 01536526740.

Reader response number 58

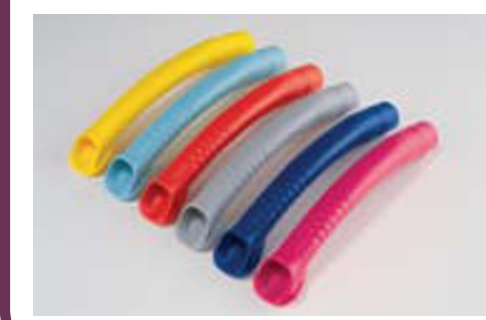

MIXING WITHOUT BUBBLES

GC Aroma Fine

DF III from GC

Europe is to replace alginate impression material GC Aroma Fine Dust Free. Manufactured in Japan, it has an advanced new lead and dust free formula of ultra-fine alginate particles with significantly enhanced powder-water affinity. This gives easier and quicker mixing without bubbles or inconsistencies, a smoother surface for exceedingly accurate impressions and a better taste with no excessive salivation.

The mixture also has ideal thixotropic properties so it flows easily under light pressure without causing gagging, a fast 'snap-set' which gives sufficient working time but reduces time in the mouth, and excellent adhesion to hydrocolloid materials.

For further information contact GC UK on 01908218999 orinfo@uk.gceurope.com.

Reader response number 59 